\title{
Relações Filogenéticas Entre Distintos Sorovares de Salmonella Enterica A Partir de Análises Comparativas de Segmentos Gênicos Associados À Virulência Empregando Ferramentas de Biologia Computacional
}

Fernanda Fernandes Pinheiro da Costa (I), Kárita Cláudia de Freitas Lidani (II), Jane Eyre Gabriel (I)

(I) UNIVASF - Universidade Federal do Vale do São Francisco (Caixa postal 91. CEP 56.302970. Petrolina, PE, Brasil), (II) UFPR - Universidade Federal do Paraná (Rua XV novembro. CEP 80.060-900, Curitiba, PR, Brasil)

\section{Resumo}

As bactérias do gênero Salmonella caracterizam-se como principais agentes microbianos típicos de contaminações alimentares e sua patogenia compreende inúmeros aspectos multifatoriais com a participação direta de múltiplos segmentos gênicos. Assim, o objetivo do presente estudo foi agrupar filogeneticamente distintos sorovares de Salmonella enterica a partir de análises comparativas de segmentos gênicos codificantes das proteínas do sistema de secreção Spa ("Surface protective antigens"), indispensáveis à patogênese desses microrganismos. Sequências de nucleotídeos codificantes das proteínas Spa de Salmonella enterica pertencentes aos seguintes sorovares Dublin (SDU29345), Gallinarium (SGU29347), Enteritidis (SEU29365), Typhisius (STU29362), Typhi (STU29363), Typhimurium (STU29364) e Senftenberg (SSU29346) foram aleatoriamente escolhidas a partir de bancos de dados de informação biológica GenBank e submetidas a análises comparativas para construção de uma árvore descritiva de agrupamentos filogenéticos empregando o programa Mega 5.0. O dendograma demonstrando as relações evolutivas entre distintos sorovares de S. enterica revelou a presença de dois ramos principais: um primeiro agrupamento resultou na detecção de um sub-ramo 
compreendendo os sorovares Dublin, Gallinarum e Enteritidis $(0,007)$ associado ao sorovar Typhisius $(0,003)$ e um segundo agrupamento demonstrou a presença de um sub-ramo constituído pelos isolados Typhi $(0,004)$ e Typhimurium $(0,003)$, que por sua vez agrupou-se ao sorovar Senftenberg $(0,002)$. Curiosamente, os resultados gerados demonstram que o agrupamento constituído pelos sorovares Typhi e Typhimurium compreendeu isolados característicos por infectarem camadas mais profundas da mucosa intestinal durante sua patogênese, enquanto os sorovares Gallinarum e Enteritidis agrupados em outro sub-ramo estão frequentemente envolvidos em casos de infecções alimentares e em contaminações de produtos avícolas. Inúmeros esforços vêm sendo despendidos a fim de investigar as relações evolutivas entre distintos sorovares de Salmonella e as descobertas descritas no presente estudo evidenciam relevantes informações acerca de epidemiologia molecular e evolutiva por análises comparativas de sequências de biomoléculas naturalmente expressas em agentes patógenos de relevância à microbiologia de alimentos.

Palavras-Chave: epidemiologia evolutiva, proteínas de secreção Spa, sorovares de Salmonella

Agência de Fomento: 